\title{
Capsule Formulation of Ethanolic Extract of Pasak Bumi (Eurycoma Longifolia Jack.,) and its Effect on Human Health Vital Signs
}

\section{Formulasi Kapsul Ekstrak Etanol Akar Pasak Bumi (Eurycoma longifolia Jack.,) dan Pengaruhnya terhadap Vital Sign Manusia Sehat}

\author{
Laela Hayu Nurani1 ${ }^{*}$, Eka kumalasari' ${ }^{1}$, Abdul Rohman² dan Sitarina Widyarini ${ }^{3}$ \\ 1Fakultas Farmasi, Universitas Ahmad Dahlan, Yogyakarta, Indonesia \\ ${ }^{2}$ Fakultas Farmasi, Universitas Gajah Mada, Yogyakarta, Indonesia \\ 3Fakultas kedokteran Hewan, Universitas Gajah Mada, Yogyakarta, Indonesia
}

\begin{abstract}
Pasak bumi (Eurycoma longifolia) has the potential to be developed as antihypertensive, antipyretic, aphrodisiacs and health supplements. The use of E. longifolia as a traditional medicine needs to be pursued in the form of more effective and appropriate formulation. The capsule preparations are easy to make and can cover the bitter taste of E. longifolia. Clinical trials in this study use design pre-post treatment in healthy humans. Subjects used were male - healthy men and healthy women who met inclusion criteria and were subjected with formulated capsule for 14 days. The study resulted capsule formula comprising of the ethanolic extract of E. longifolia $300 \mathrm{mg}$, vivapur $101300 \mathrm{mg}, 58 \mathrm{mg}$ maydis starch, aerosil 3\%, talc 2\%, and Mg stearate 1\%. The results showed that the capsule of E. longifolia did not affect the value of heart rate, respiration rate, body temperature and weight $(P>0.05)$, based on paired $t$-test, but they causes a decrease in blood pressure of healthy human. The ethanol extract of E. longifolia caused vasodilation of blood vessels that can be used in antihypertensive therapy.
\end{abstract}

Keywords: Eurycoma longifolia, capsules, vital sign.

\begin{abstract}
ABSTRAK
Akar pasak bumi (E. Longifolia) memiliki potensi untuk dikembangkan menjadi obat tradisional yang berfungsi sebagai antihipertensi, antipiretik, afrodisiaka dan suplemen kesehatan. Penggunaan akar pasak bumi sebagai obat tradisional perlu diupayakan dalam bentuk sediaan yang lebih efektif dengan dosis yang lebih tepat. Sediaan yang mudah dibuat dan dapat menutup rasa pahit dari akar pasak bumi yaitu berupa kapsul. Formula kapsul dengan bahan tambahan vivapur 101 sebesar 300 mg, amilum maydis 58 mg, aerosil 3\%,talk 2\%, Mg. Stearat 1\% untuk dosis ekstrak etanol akar pasak bumi sebagai imunostimulansia 300 $\mathrm{mg} / \mathrm{kapsul}$, Kapsul dengan formula yang tepat dan telah dilakukan evaluasi sediaan dapat digunakan dalam pelayanan kesehatan forma dengan melewati uji keamanan sediaan pada manusia sehat. Pararemeter yang diukur adalah heart rate, respiration rate, suhu tubuh, berat badan, dan tekanan darah . Uji klinis pada penelitian ini menggunakan design pre-post treatment pada manusia sehat. Subjek yang digunakan adalah 10 laki-laki sehat dan 10 perempuan sehat yang memenuhi kriteria inklusi yang selama 14 hari diberikan kapsul ekstrak etanol akar pasak bumi yang sudah diformulasi. Data penelitian dianalisis statistik menggunakan uji paired T-test. Hasil uji menunjukkan bahwa kapsul ekstrak etanol akar pasak bumi tidak mempengaruhi nilai heart rate, respiration rate, suhu tubuh dan berat badan namun menyebabkan penurunan tekanan darah manusia sehat. Ekstrak etanol akar pasak bumi menyebabkan vasodilatasi pembuluh darah sehingga dapat digunakan dalam terapi antihipertensi.
\end{abstract}

Kata Kunci : Akar pasak bumi, kapsul, vital sign.

\section{PENDAHULUAN}

Pasak bumi (Eurycoma longifolia Jack) merupakan salah satu tanaman herbal tropis yang sangat populer di negara-negara Asia Tenggara.

Correspondence author: Laela Hayu Nurani Email : laelafarmasi@yahoo.com
Akar dari tanaman ini biasanya digunakan untuk mengobati rasa sakit, meningkatkan gairah seksual, bengkak kelenjar dan sebagai suplemen kesehatan (Kuo et al., 2003). Pasak bumi juga bisa digunakan sebagai anti tumor dan anti plasmoidal (Jiwajinda et al., 2002), sitotoksik, antimalaria, antiulcer, antipiretik (Tee dan Azimahtol, 2005). 
Selain itu, akar pasak bumi berkhasiat sebagai antihiperglikemi (Husen et al., 2004). Kandungan kimia akar pasak bumi sangat beragam. Tanaman ini mengandung beberapa macam kuasinoid yang bertanggung jawab terhadap rasa pahit, triterpen triscullane, turunan skualen, bifenil-neo-lignan, xantin-6-on dan alkaloid $\beta$-karbolin (Bedir et al., 2003). Sediaan yang mudah dibuat dan dapat menutupi rasa pahit dari akar pasak bumi serta mudah ditelan maka dibuatlah sediaan kapsul (Augsburger, 2000).

Upaya agar obat tradisional dapat diterima di pelayanan kesehatan formal/profesi dokter, maka hasil data empirik harus didukung oleh bukti ilmiah adanya khasiat dan keamanan penggunaannya pada manusia. Uji klinik pada manusia hanya dapat dilakukan apabila obat tradisional/obat herbal tersebut telah terbukti aman dan berkhasiat pada uji preklinik (Dewoto, 2007).

Penelitian Henkel et al. (2013) menyebutkan bahwa $200 \mathrm{mg}$ ekstrak air akar pasak bumi yang diberikan 2 kali sehari selama 5 minggu kepada laki-laki dan perempuan dapat digunakan sebagai suplemen herbal yang tidak memiliki efek samping dan dapat meningkatkan kekuatan otot yang signifikan pada laki-laki. Hal ini sejalan dengan penelitian lain yang menyebutkan bahwa pemberian ekstrak air akar pasak bumi terstandar dosis 1,2 gram dua kali sehari selama 14 hari bersifat aman dan tidak menimbulkan efek samping yang berbahaya (Hayati, 2013).

Upaya meningkatkan keamanan penggunaan akar pasak bumi sebagai terapi preventif diperlukan pengukuran vital sign (tekanan darah, heart rate, respiration rate, berat badan dan suhu tubuh). Vital sign digunakan untuk mengukur fungsi dasar tubuh membantu menilai kesehatan fisik secara umum untuk memberikan petunjuk untuk penyakit yang mungkin ada (Schriger, 2007).

\section{METODOLOGI}

\section{Bahan dan alat}

Penelitian ini menggunakan desain penelitian eksperimental untuk memperoleh formula kapsul ekstrak etanol akar pasak bumi yang tepat. Uji klinik pada manusia sehat menggunakan desain pre-post treatment.

Bahan yang digunakan dalam penelitian ini adalah akar pasak bumi (Eurycoma longifolia Jack) yang diperoleh dari Kalimantan Selatan. Etanol 70 $\%$, vivapur 101, talk, Mg Stearat, aerosil, amilum maydis, dan cangkang kapsul gelatin diperoleh dari Bratachem Yogyakarta.

\section{Ekstraksi sampel}

Akar pasak bumi dikeringkan di Laboratorium Teknologi Sediaan Farmasi Universitas Ahmad Dahlan (UAD) Yogyakarta, dan dihaluskan menjadi serbuk. Lakukan pemeriksaan standarisasi simplisia. Selanjutnya pembuatan ekstrak dilakukan dengan merendam $2,5 \mathrm{~kg}$ serbuk ke dalam etanol (70\%) sebanyak 8 liter diaduk dengan stirer selama 3 jam kemudian didiamkan selama 24 jam. Filtrat diuapkan dengan rotary evaporator dengan suhu $60{ }^{\circ} \mathrm{C}$ sampai diperoleh ekstrak kental. Proses ekstraksi dilakukan sebanyak 8 kali untuk memperoleh jumlah ekstrak yang lebih banyak.

\section{Formulasi Kapsul}

Formula dari kapsul ekstrak etanol akar pasak bumi (Tabel I).

Tabel I. Formula kapsul ekstrak etanol akar pasak bumi (Roselyndiar, 2012)

\begin{tabular}{lcc}
\hline \multicolumn{1}{c}{ Komponen } & Formula & Fungsi \\
\hline Ekstrak kental & $300 \mathrm{mg}$ & Zat aktif \\
Vivapur 101 & $300 \mathrm{mg}$ & adsorben \\
Amilum jagung & $58 \mathrm{mg}$ & pengisi \\
Aerosil & $3 \%$ & adsorben \\
Talk & $2 \%$ & glidan \\
Mg. Stearat & $1 \%$ & lubrikan \\
Bobot Total & $700 \mathrm{mg}$ & \\
\hline
\end{tabular}

Ekstrak kental dikeringkan dengan penambahan vivapur 101, amilum maydis, talk, Mg. stearat dan aerosil. Masukkan campuran tersebut kedalam cangkang kapsul gelatin. Sediaan di evaluasi keseragaman bobotnya, waktu hancur dan higroskopisnya.

\section{Uji Klinik}

Penelitian Uji klinik menggunakan desain pre-post treatment. Parameter nilai tekanan darah, heart rate, respiration rate, suhu tubuh dan berat badan dari probandus diukur sebelum (hari ke-0) dan sesudah mengkonsumsi kapsul berisi $300 \mathrm{mg}$ ekstrak etanol akar pasak bumi selama 14 hari (hari ke-15). Adapun kriteria inklusi dari penelitian ini ialah probandus yang dibuktikan dengan surat keterangan sehat, tidak merokok, tidak mengkonsumsi obat, tidak mengkonsumsi vitamin atau suplemen kesehatan dan Laki-laki dan wanita berumur 18 - 55 th serta bersedia menjadi subjek. Adapun kriteria Eksklusi pada penelitian ini yaitu Probandus tidak kooperatif selama penelitian berlangsung, wanita hamil dan wanita menyusui. Pemeriksaan vital sign dilakukan oleh dokter yang memiliki izin praktek. 


\section{HASIL DAN KESIMPULAN}

Data hasil puji keseragaman bobot (Tabel II). Berdasarkan persyaratan Farmakope Indonesia edisi III bahwa kapsul dengan bobot rata-rata lebih dari $120 \mathrm{mg}$ tidak boleh memiliki perbedaan dalam persen bobot isi tiap kapsul terhadap bobot rata-rata isi kapsul lebih dari 7,5\% dan 15\%. Berdasarkan penimbangan kapsul untuk uji keseragaman bobot menunjukkan tidak ada yang menyimpang lebih dari persyaratan. Hal ini menunjukkan bahwa formula memenuhi kriteria untuk keseragaman bobot.

Kapsul dapat memberikan efek terapi jika terlebih dahulu hancur menjadi partikel yang lebih kecil, agar isi kapsul dapat terabsorbsi pada saluran cerna. Uji waktu hancur untuk kapsul menunjukkan waktu hancur rata-rata \pm 1 menit 35 detik. Hasil uji waktu hancur menunjukkan bahwa semua formula memenuhi syarat uji waktu hancur kapsul Farmakope Indonesia edisi III yaitu waktu hancur di bawah 15 menit (Tabel III).

Tabel II. Data keseragaman bobot kapsul ekstrak etanol akar pasak bumi

\begin{tabular}{cccc}
\hline Replikasi & $\begin{array}{c}\text { Netto } \\
\text { bobot (g) }\end{array}$ & Replikasi & $\begin{array}{c}\text { Netto bobot } \\
\text { (g) }\end{array}$ \\
\hline 1 & 0,354 & 11 & 0,349 \\
2 & 0,353 & 12 & 0,356 \\
3 & 0,354 & 13 & 0,353 \\
4 & 0,356 & 14 & 0,352 \\
5 & 0,353 & 15 & 0,355 \\
6 & 0,35 & 16 & 0,353 \\
7 & 0,357 & 17 & 0,354 \\
8 & 0,357 & 18 & 0,35 \\
9 & 0,357 & 19 & 0,353 \\
10 & 0,357 & 20 & 0,353 \\
& Rata-rata & & 0,3538 \\
\multicolumn{5}{c}{ CV } & & 0,68378 \\
\hline
\end{tabular}

Tabel III. Data waktu hancur kapsul ekstrak etanol akar pasak bumi

\begin{tabular}{cc}
\hline Replikasi & Waktu Hancur Kapsul \\
\hline 1 & 1 menit 36 detik \\
2 & 1 menit 33 detik \\
3 & 1 menit 36 detik \\
4 & 1 menit 36 detik \\
5 & 1 menit 33 detik \\
6 & 1 menit 33 detik \\
Rata-rata & 1 menit 35 detik \\
CV & 1,2148 \\
\hline
\end{tabular}

Uji higroskopis dilakukan dengan dengan mengamati perubahan bobot dan warna dari isi sedian kapsul selama satu bulan. Perubahan bobot kapsul dan warna isi kapsul setiap waktunya dapat menggambarkan perubahan kadar air yang terdapat dalam sediaan (Tabel IV).

Tabel 4. Data higroskopis kapsul hari ke-1 sampai hari ke-4

\begin{tabular}{ccccc}
\hline R & & $\mathbf{1}$ & $\mathbf{2}$ & $\mathbf{3}$ \\
\hline & 1 & 0,431 & 0,427 & 0,432 \\
& 2 & 0,431 & 0,427 & 0,432 \\
Bobot (g) & 3 & 0,431 & 0,427 & 0,432 \\
& 4 & 0,431 & 0,427 & 0,432 \\
& 5 & 0,431 & 0,427 & 0,432 \\
& 6 & 0,431 & 0,427 & 0,432 \\
& 7 & 0,432 & 0,428 & 0,433 \\
\hline
\end{tabular}

Berdasarkan hasil pengamatan bobot formula tidak menunjukkan perubahan yang signifikan hanya terjadi penambahan bobot $1 \mathrm{mg}$ sampai hari ke-4. Pengamatan warna isi sediaan kapsul juga masih tetap menunjukkan warna kecoklatan. Hal ini menunjukkan selama satu minggu formula masih stabil dan belum terjadi perubahan warna.

Ekstrak adalah bahan yang bersifat higroskopis sehingga mudah menyerap air. Dalam hal ini sediaan dapat tetap stabil dikarenakan penggunaan Vivapur 101 sebagai pembuatan serbuk ekstrak. Vivapur ini juga memiliki sifat sebagai adsorben. Jumlah penggunaan yang cukup besar dengan perbandingan Ekstrak kental:Vivapur 101 (1:1) menghasilkan serbuk kering sediaan lebih kering, halus, mudah homogen dan stabil. Selain itu, penambahan aerosil sebagai adsorben untuk melindungi bahan berkhasiat dari pengaruh kelembaban, membantu meningkatkan homogenitas campuran, dan menghindari lembab akibat reaksi antar bahan.

Penelitian uji klinis menggunakan probandus sebanyak 10 orang wanita dan 10 orang laki-laki. Pemeriksaan vital sign dilakukan di hari ke-15 dilakukan oleh seorang dokter yang meliliki izin praktek (Tabel V).

Uji distribusi normal data vital sign dilakukan dengan menggunakan uji Shapiro-Wilk karena jumlah sampel yang kurang dari 50. Pada pemeriksaan vital sign terdapat 2 parameter yang tidak terdistribusi normal baik pada hari ke-0 maupun pada hari ke-15 yaitu nilai sistol dan RR dengan nilai signifikansi yang kurang dari 0,05 diuji menggunaakan taraf kepercayaan 95\% maka dapat dilanjutkan dengan uji Wilcoxon. Data Parameter nilai diastol, heart rate (HR), berat badan (BB) dan $\mathrm{T}$ (suhu tubuh) terdistribusi normal karena nilai signifikansi yang lebih dari 0,05 maka dapat dilanjutkan dengan uji Paired sample T-test. 
Tabel V. Nilai pemeriksaan vital sign Data vital sign probandus pada hari ke 0 dan hari ke-15 probandus pemberian kapsul ekstrak etanol akar pasak bumi

\begin{tabular}{clll}
\hline Parameter & \multicolumn{2}{c}{ Rata-rata } & Sig. \\
\hline \multirow{2}{*}{ Sistol } & Hari ke-0 & 122,5 & 0,01 \\
& Hari ke-15 & 108,75 & \\
\multirow{2}{*}{ Diastol } & Hari ke-0 & 77,5 & 0,157 \\
& Hari ke-15 & 75 & \\
HR & Hari ke-0 & 88 & 0,416 \\
& Hari ke-15 & 82 & \\
RR & Hari ke-0 & 27,5 & 0,109 \\
& Hari ke-15 & 22 & \\
BB & Hari ke-0 & 47,625 & 0,218 \\
& Hari ke-15 & 46,825 & \\
\multirow{2}{*}{ T } & Hari ke-0 & 36,3 & 0,527 \\
\hline
\end{tabular}

Hasil penelitian (Tabel V). menunjukan bahwa terjadi perubahan penurunan rata-rata nilai seluruh vital sign pada hari ke-15. Namun, setelah dilakukan analisis statistik uji Paired Sample T-test dan Uji Wilcoxon diketahui bahwa semua nilai parameter vital sign menunjukkan nilai tidak berbeda signifikan kecuali nilai sistol yang menunjukkan ada perbedaan nilai hari ke 0 dan hari ke 15 setelah probandus diberikan kapsul akar pasak bumi.

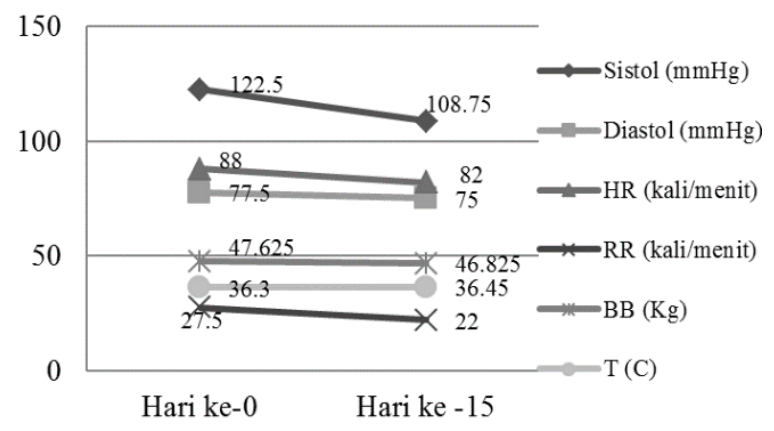

Gambar 1. Data vital sign probandus pada hari ke 0 dan hari ke-14 pemberian kapsul ekstrak etanol akar pasak bumi

Data hari ke 0 TD dan HR probandus menunjukkan range nilai normal. Rata-rata tekanan darah normal biasanya 120/80 mmHg. Untuk mengukur tekanan darah maka perlu dilakukan pengukuran tekanan darah secara rutin (Smeltzer \& Bare, 2001). Tekanan darah probandus sebelum dan setelah diberikan kapsul akar pasak bumi menunjukkan perubahan penurunan rata-rata dan setelah dilakukan uji statistik menghasilkan nilai berbeda signifikan.
Hal ini sejalan dengan hasil penelitian pada tikus terhadap relaksasi aorta oleh Tee, dkk (2016) yang menunjukkan hasil bahwa ekstrak etanol akar pasak bumi menyebabkan vasodilatasi pembuluh, sehingga dapat menurunkan tekanan darah. Usia muda prevalensi hipertensi lebih tinggi pada pria dibandingkan pada wanita, sedangkan pada usia lanjut tekanan darah lebih tinggi pada wanita dibandingkan pada pria (Kearney et al, 2005).

Heart rate probandus sebelum dan setelah diberikan kapsul akar pasak bumi menunjukkan tidak berbeda signifikan dan masuk kategori normal karena Frekuensi denyut nadi dihitung dalam 1 menit, normalnya 60-100 kali/menit. Hal ini sama dengan hasil penelitian yang dilakukan Mokhtar dkk (2014) pada tikus bahwa ekstrak akar pasak bumi secara signifikan mengurangi tekanan perfusi koroner (CPP) namun tidak ada perubahan yang signifikan tekanan ventrikel kiri (LVDP dan denyut jantung (HR). Denyut nadi seseorang akan terus meningkat bila suhu tubuh meningkat kecuali bila pekerja yang bersangkutan telah beraklimatisasi terhadap suhu udara yang tinggi (Muffichatum, 2006).

Akar pasak bumi secara signifikan dapat meningkatkan jumlah testosteron dan progesteron yang diproduksi oleh testis tikus (Eng, 2007). Selain itu ekstrak akar pasak bumi dapat mengaktifkan enzim yang mengkonversi pregnenolon menjadi progesteron dan mengkonversi 17-OH pregnenolon menjadi dehydropiandrosterone dan kemudian menjadi testosteron. Testosteron secara klinis dapat mengurangi kejadian miokard iskemi pada pasien dengan angina koroner dengan dilatasi arteri dan meningkatkan aliran darah koroner (Pugh, et al, 2002). Hormon ini juga menghasilkan relaksasi arteri pada kontrol sehat, pasien dengan gagal jantung dan laki-laki dengan defisiensi androgen (Malkin et al., 2006).

Suhu tubuh probandus sebelum dan setelah diberikan kapsul akar pasak bumi menunjukkan tidak berbeda signifikan dan berada dalam suhu normal. Suhu tubuh probandus normal karena suhu rata-rata normal umumnya antara $98,0^{\circ} \mathrm{F}$ $\left(36,6^{\circ} \mathrm{C}\right)$ dan $98,6^{\circ} \mathrm{F}\left(37^{\circ} \mathrm{C}\right)$ ketika diukur secara oral (Schriger, 2007). Hasil ini sejalan dengan penelitian yang dilakukan oleh Muhammad dkk (2010) terhadap laki-laki yang diberikan $75 \mathrm{mg}$ kapsul akar pasak bumi 2 kali sehari selama 7 hari tidak menunjukkan adanya perbedaan signifikan pada suhu tubuh sebelum dan sesudah perlakuan. Sejauh ini di laporkan bahwa efek samping penggunaan akar pasak bumi dalam jumlah besar dapat menyebabkan sulit tidur dan meningkatkan suhu tubuh (Minorsky, 2004). Oleh karena itu 
penting perlu dilakukan pengukuran suhu tubuh probandus sebelum dan sesudah perlakuan.

Berat badan probandus sebelum dan setelah diberikan kapsul akar pasak bumi menunjukkan tidak berbeda signifikan, hal ini sejalan dengan penelitian terhadap Ahmad dkk (2011) Tikus galur SD yang diberikan $8 \mathrm{mg} / \mathrm{kg}$ ekstrak air akar pasak bumi secara IM satu kali sehari selama 6 minggu tidak menunjukkan perbedaan secara signifikan sebelum dan sesudah perlakuan. Bobot tikus tetap stabil selama penelitian. Penelitian juga dilakukan terhadap berat badan tikus galur SD yang berumur 1 tahun dengan bobot 370-500 g yang diberikan ekstrak kering akar pasak bumi sebanyak $15 \mathrm{mg} / \mathrm{kg}$ selama 6 minggu menunjukkan bahwa tidak ada perbedaan signifikan antara kontrol dan kelompok perlakuan (Ariff, et al, 2012).

Respiration rate probandus sebelum dan setelah diberikan kapsul akar pasak bumi menunjukkan tidak berbeda signifikan.Tingkat respirasi di bawah 12 atau di atas 25 napas per menit saat beristirahat dianggap abnormal. Di antara kondisi yang dapat mengubah tingkat pernapasan normal asma, kecemasan, pneumonia, gagal jantung kongestif, penyakit paru-paru, penggunaan narkotika, atau overdosis obat (Schriger, 2007)

Penelitian klinis terhadap laki-laki usia 4065 tahun yang diberikan Eurycoma longifolia (Physta) and Polygonum minus selama 12 minggu menunjukkan tidak ada perbedaan yang signifikan dalam tanda-tanda vital, berat badan antara kontrol dibandingkan dengan probandus. Selain itu tidak ada perubahan yang signifikan pada kontrol dibandingkan probandus terhadap hasil fungsi hati dan ginjal yang relevan nilai-nilai, termasuk albumin, AST, ALT, alkali fosfatase, bilirubin, BUN, kreatinin, dan GFR dihitung (Udani et al, 2014).

\section{KESIMPULAN}

Penelitian ini memperoleh Formula yang tepat terhadap kapsul ekstrak etanol akar pasak bumi (Eurycoma longifolia Jack.,). Kapsul ekstrak etanol akar pasak bumi tidak mempengaruhi nilai berat badan, suhu tubuh heart rate dan respiration rate namun berpengaruh pada nilai sistol probandus sehat.

\section{UCAPAN TERIMAKASIH}

Terimakasih disampaikan kepada DIKTI atas hibah Tim Pascasarjana tahun anggaran $2015 / 2016$.

\section{DAFTAR PUSTAKA}

Ahmad, N.S., Nazrun, S., Mohd, F.A.B., Tajul, A.BS., Norliza M., Norazlina M., \& Ima NS., 2011. The anti-osteoporotic effect of Eurycoma Longifolia in aged orchidectomised rat mode. Aging Male 14(3): 150-154.

Ariff, A.S.T., Ima, N.S., Pramanik., J., \& Ahmad, N.S., 2012. Effects of Eurycoma longifolia on Testosterone Level and Bone Structure in an Aged Orchidectomised Rat Model. Evidence-Based Complementary and Alternative Medicine, Article ID 818072, 7 pages

Augsburger, L.L., 2000. Modern Pharmaceutics: Hard and Soft Gelatin Capsules, (2 ${ }^{\text {nd }}$ Ed.), New York: Mercel Dekker.

Bedir, E., Gazar, H., A., Ngwendson, J., N., \& Khan, I., A., 2003, Eurycomaoside: A New Quassinoid-Type Glycoside from the Roots of Eurycoma longifolia. Chemical and Pharmaceutical Bulletin 51: 1301-1303.

Dewoto, H.R., 2007, Pengembangan Obat Tradisional Indonesia Menjadi Fitofarmaka. Majalah Kedokteran Indonesia 57: 7-11.

Eng, A,. 2007. Correcting systemic androgen levels using Eurycoma longifolia. U.S. Patent Application 11/176,464, filed July 7, 2005, U.S. patent 20070009621.

Hayati, F., 2013,. Uji Praklinik dan Uji Klinik Fase I Ekstrak Air Akar Pasak Bumi (Eurycoma longifolia Jack) Terstandar sebagai Afrodisiaka, Disertasi, Fakultas Kedokteran Universitas Gadjah Mada, Yogyakarta.

Henkel, R. R., et al, 2013. Tongkat Ali as a Potential Herbal Supplement for Physically Active Male and Female Seniors-A Pilot Study. Phytotherapy Research 28(4): 44-50.

Kearney, P.M., Whelton, M., Reynolds, K., Muntner, P., Whelton, P.K., \& He, J. 2005, Global burden of hypertension: analysis of worldwide data. Lancet 2005; 365: 217-23.

Malkin, C.J., Jones, R.D., Jones, T.H., Channer, K.S., 2006. Effect of testosterone on ex vivo vascular reactivity in man. Clinical Sciences 111: 265-74.

Minorsky, P.V, 2004. On the inside. Plant Physiology 131(3):1157-1158.

Mokhtar, R.H., Abdullah, N., \& Ayob A., 2014. Effects of Eurycoma Longifolia Extract on the Isolated Rat Heart. The international Medical Journal Malaysia 13: 1-10.

Muffichatum, 2006. Hubungan antara Tekanan Panas, Denyut Nadi dan Produktivitas Kerja pada pekerja Pandai Besi Paguyuban Wesi Aji Dororejo Batang. http://digilib.unnes.ac.id. Diakses pada tanggal 12 Agustus 2016 
Muhamad, AZ., Keong, C.C., Kiew, O.F., Abdullah., M.R., Lam., C.K., 2010. Effects of Eurycoma longifolia Jack supplementation on recreational athletes' endurance running capacity and physiological responses in the heat. International Journal of Applied Sports Sciences 22(2): 1-19.

Novianti, S, 2015. Pemberian ekstrak etanol akar pasak bumi secara oral meningkatkan kadar hormon testosterone tikus wistar jantan tua, Tesis, Program Pasca Sarjana Universitas Udayana, Denpasar, Bali.

Pugh, P.J., Jones, R.D., Jones, T.H., Channer, K.S., 2002. Intrinsic response of rat coronary arteries in vitro. Endocrine 19: 155-61.

Roselyndiar, 2012, Formulasi Kapsul Kombinasi Ekstrak Herba Seledri (Apium graveolens L.) dan Daun Tempuyung (Sonchus arvensis L.), Skripsi, Fakultas MIPA, Universitas Indonesia
Schriger, D.L., 2007, Approach to the patient with abnormal vital signs. Goldman L, Ausiello D. Cecil Textbook of Medicine. $23^{\text {rd }}$ Ed. Philadelphia, USA: Elsevier.

Tee, B.H., Hoe, S.Z., Cheah, S.H., Lam, S.K., 2016, First Report of Eurycoma longifolia Jack Root Extract CausingRelaxation of Aortic Rings in Rats. BioMed Research International Volume 2016, Article ID 1361508, 9 pages.

Udani, J.K., Annie, A.G., Mufiza, M., Michael, N.P., Azreena, A., 2013. Effects of a Proprietary Freeze-Dried Water Extract of Eurycoma longifolia (Physta) and Polygonum minus on Sexual Performance and Well-Being in Men: A Randomized, Double-Blind, PlaceboControlled Study. Evidence-Based Complementary and Alternative Medicine, Article ID 179529, 10 pages. 